\title{
Judicial Dialogue in Social Media Cases in Europe: Exploring the Role of Peers in Judicial Adjudication - CORRIGENDUM
}

E. Psychogiopoulou

https://doi.org/10.1017/glj.2021.57, Published by Cambridge University Press on behalf of the German Law Journal, 15 September 2021

Keywords: judicial dialogue; social media; national courts; CJEU; ECtHR

The author apologises that the funding details below, including grant number, were missing from the article on its original publication. The article (in its PDF and HTML formats) has been updated to include this funding information in the unnumbered footnote, after the sentences about the author's research background. This corrigendum has been published in order to be transparent about the change to the scholarly record.

"Research for this article received funding from the European Union's Horizon 2020 Programme in the framework of the COMPACT project (grant agreement H2020-ICT-2016-2 No. 762128). Warm thanks go to the project's national experts in the countries under study for the collection of social media case law and Dr Federica Casarosa and Dr Anna Kandyla for their fruitful collaboration."

The online version of this article has been updated to list the authors correctly.

\section{Reference}

Psychogiopoulou, E. (2021). Judicial Dialogue in Social Media Cases in Europe: Exploring the Role of Peers in Judicial Adjudication. German Law Journal, 22(6), 915-935. doi: 10.1017/glj.2021.57

Cite this article: Psychogiopoulou E (2021). Judicial Dialogue in Social Media Cases in Europe: Exploring the Role of Peers in Judicial Adjudication - CORRIGENDUM. German Law Journal 22, 1385. https://doi.org/10.1017/glj.2021.68 